\title{
The Hidden Perils of Affirmative Action: Sabotage in Handicap Contests*
}

\author{
Alasdair Brown ${ }^{\dagger}$ \\ Subhasish M. Chowdhury \\ University of East Anglia \\ University of East Anglia
}

August 9, 2016

\begin{abstract}
Contests are ubiquitous in economic, organizational and political settings. Contest designers often use tools to make a contest among asymmetric contestants more even, in order to either elicit higher effort levels, or for ethical reasons. Handicapping - in which stronger participants are a priori weakened - is one successful tool that is widely used in sports, promotional tournaments and procurement auctions. In this study we show theoretically that participants may also increase their destructive effort, and sabotage their rivals' performance, when handicapping is employed. We empirically verify this prediction using data on 19,635 U.K. horse-races in 2011 and 2012. Our results suggest that while a level field may be conducive to heightened positive effort in general, in a setting where both handicapping and sabotage are present it also lays the ground for greater destruction.
\end{abstract}

JEL Classification: C3, C72, D72, D74, J24

Keywords: sabotage, contests, contest design, superstars, handicapping, horse racing

*We would like to thank the Co-Editor, Ragan Petrie, an Associate Editor, and two anonymous referees for very helpful comments. We are also grateful to Peter Dawson, Alan Gelder, Oliver Gürtler, Bruce Lyons, Dave Malueg, the participants at the 2012 Public Choice World Congress, the 2012 Southern Economic Association Annual Meeting, the 5th Young Researchers Workshop in Contests and Tournaments in Dortmund, the 17th Colloquium in Personnel Economics in Cologne, and seminar participants at the Universities of East Anglia, Erasmus Rotterdam, Munich, Seoul National, St. Gallen and Zurich for feedback and suggestions. Ollie Woodcock and Kimberley Wheeler provided excellent research assistance. Any remaining errors are our own.

${ }^{\dagger}$ School of Economics, University of East Anglia. Email: alasdair.brown@uea.ac.uk

${ }^{\ddagger}$ School of Economics, Centre for Behavioural and Experimental Social Science, and Centre for Competition Policy, University of East Anglia. Email: s.modak-chowdhury@uea.ac.uk 


\section{Introduction}

Contests, in which individuals have the opportunity to expend costly resources in order to affect the probabilities of winning a prize, are ubiquitous in everyday life. Examples include promotion tournaments, political races, rent-seeking, elections, sports, and various market competitions such as advertising or patent races (see Konrad (2009) for a broader discussion). In many of these situations, a contest designer plans a contest with certain objectives in mind. In sports, promotional tournaments, and social contests with positive externalities - to name a few - maximizing total effort is usually the central objective.

The potential participants of a contest do not necessarily have even abilities or efficiencies. A sufficiently uneven contest, however, has several disadvantages. It may fail to give a level playing field to a historically disadvantaged or minority group. As a result, contestants from a minority group may decide not to participate in the contest. It can also fail to elicit significant efforts from weaker participants if they perceive their probability of winning to be too small (Lazear and Rosen (1981) and Runkel (2006)). Knowing this, a stronger participant also has limited incentives to exert high effort, and the overall effort exerted in a sufficiently uneven contest is usually low. Hence, ex-ante differences in efficiencies or abilities among participants are a matter of concern for a contest designer interested in maximizing total effort.

In this context, Brown (2011) empirically finds that the presence of a 'superstar' - in this case, an in-form Tiger Woods - serves to reduce the absolute performance (and implicitly, the effort) of his fellow professional golfers. Sunde (2009) finds a similar effect in women's professional tennis.

It would be natural, therefore, to conclude that a contest designer should aim to level the playing field, since it will make the contestants exert more effort. Handicapping - where stronger participants are a priori weakened - is one such tool that is widely used in sports, promotional tournaments and other types of contests. Firms that use contests as a motivational tool often handicap those of superior ability, or give head-starts to those with inferior ability. Similarly, expenditure in political campaigns is often capped - thereby handicapping the candidate with the richest connections (Che and Gale (1998)). It is also common to 
observe handicapping of an outsider in a local procurement auction, or in internal promotional tournaments (Chan (1996)). One extreme policy used to handicap the most efficient players is to exclude them altogether (Baye et al. (1993)). All these designs are implemented essentially to 'level the playing field' for all the participants, to rescale the ex-ante likelihood of winning for all the participants, and to incentivize participants to exert higher levels of efforts in the contest. In sports this is known as 'competitive balance' and is an important component when designing sports tournaments (Szymanski (2003), Fort and Maxcy (2003)).

Economists have also studied and analyzed the effects of handicapping in the context of affirmative action. Overall, both theoretical and applied results support an employment of affirmative action tools in the interests of higher effort as well as equality. Fryer and Loury (2005) show that profile-specific affirmative actions can increase effort, and reduce inequality. $\mathrm{Fu}(2006)$ shows that such policies may improve incoming test scores for an academic institution, while still admitting students from minority backgrounds. Similar results are confirmed in different contest structures and information settings by Franke (2012a) and Calsamiglia et al. (2013). Kirkegaard (2012) lays down mechanisms by which an affirmative action policy can also improve effort. Empirically, the issue of levelling the playing field is supported by Schotter and Weigelt (1992), who run a laboratory experiment with equal opportunity programs and affirmative actions. They show that such policies benefit the disadvantaged group and at the same time increase the effort levels of all contestants. In addition, Balafoutas and Sutter (2012) focus on the effect of various types of affirmative action on the participation and performance of females in tournaments. They find that females are more likely to enter competitions, and perform equally well or better, when affirmative action is used. Along the same lines, Niederle et al. (2013) show that implementing affirmative action increases the entry of females, and the benefit overshadows the cost of affirmative action. Furthermore, in a similar setting as Brown (2011), Franke (2012b) investigates the area of amateur golf tournaments and shows that handicapping the efficient players elicits higher effort in the tournament. However, Girard (2016) shows, with data from Northern India, that the effect of affirmative action - a mandatory quota in the local assembly for lower caste people - stops once the mandatory quota is taken out.

Despite the predominant success of handicapping/affirmative action, implementation of 
such policies is not without danger. Contests between participants of comparable ability may see more effort diverted to destruction (i.e., sabotage), rather than production. ${ }^{1}$ In a political race this may take the form of negative smear campaigning, rather than a positive focus on the issues (Skaperdas and Grofman (1995)). In a firm, sabotage could involve the spreading of malicious rumours about a colleague (Lazear (1989)). In markets, this may mean negative advertising or even introducing ways to increase rivals' costs (Salop and Scheffman (1983)). On a football (soccer) pitch, this may mean using fouls to stop rival teams scoring (Deutscher et al. (2013)). Regardless of the setting, any increase in sabotage is to the detriment of the contest designer. Fallucchi and Quercia (2016) find that introducing an affirmative action policy increases the entry rate and performance of the disadvantaged group, but retaliation may also increase. In a similar way, Leibbrandt et al. (2015) find that introducing gender quotas may increase sabotage against women; they find that sabotage is directed specifically towards women by women. Up until now, however, no study has attempted to investigate whether the policies used to elicit higher effort, or reduce inequality, actually increase sabotage in a field setting. In this paper we aim to answer this question.

We analyse an environment in which there is both handicapping and sabotage, by examining 19,635 horse races run in the U.K. in 2011 and 2012. ${ }^{2}$ Of these, 11,766 (59.9\%) are handicap races. In handicap races, horses within a range of abilities are permitted to take part, but superior horses are given heavier weights so that all horses have a similar probability of winning. ${ }^{3}$ The British Horse Racing Authority (BHA) Guide to Handicapping states

\footnotetext{
${ }^{1}$ Sabotage in static and dynamic contests has been considered by a number of authors (e.g. Lazear (1989), Konrad (2000), Chen (2003), Kräkel (2005), Amegashie and Runkel (2007), Münster (2007), Soubeyran (2009) and Gürtler and Münster (2010)). Although experimental evidence has been forthcoming (e.g. Harbring et al. (2007), Harbring and Irlenbusch (2008) and Carpenter et al. (2010)) - see Dechenaux et al. (2015) for a survey - there has been relatively little field analysis. Notable exceptions include the work of Garicano and Palacios-Huerta (2014), del Corral et al. (2010), Balafoutas et al. (2012) and Deutscher et al. (2013) who examine fouls, as a form of sabotage, in sports. Please see Chowdhury and Gürtler (2015) for a comprehensive survey on sabotage in contests.

${ }^{2}$ Horse racing has been used by other authors to examine contest theory. For example, Lynch (2005) uses Arabian horse racing data to examine how the structuring of the prize schedule, and the translation of effort into reward, affects aggregate effort in contests. Coffey and Maloney (2010) use horse and dog racing data to disentangle the effect of incentives and selection on effort in contests.

${ }^{3}$ Full details on the handicapping system in horse racing can be found on the British Horse Racing
} 
that

'A handicap is a race for which horses are allotted weight, based on their ability on the racecourse, to try to equalize their chances of winning... The Handicapper hopes to make the race exciting and competitive for the owners and racegoers'

There is also a second ingredient to our data. The BHA investigates 'interference' between horses during each race. Interference can include one horse knocking into another horse, a horse forcing another off their racing line, and even cases of a jockey stealing another jockey's whip during the race. ${ }^{4}$ While interfering with another horse, the jockey is exerting effort to reduce the likelihood of the victim winning. Interference is, in other words, sabotage. In 2011 and 2012 alone, there were 1,099 cases of interference.

We find that participants in handicap races are substantially more likely to commit sabotage than those competing in non-handicap races. The incidence of sabotage is particularly high in close handicap races (as measured by the standard deviation in pre-race odds), and even extends to close non-handicap races. In other words, a levelling of the field appears to increase the likelihood of destruction in contest environments. Furthermore, we find that there are strong incentives for jockeys to employ destructive strategies as it helps the saboteur to improve his/her final rank and to win the race. The enactment of sabotage gains the saboteur 1.43 places, on average, relative to the betting market's pre-race expectations of their finishing position. Combining these results, we conclude that if not taken care of, sabotage may partially offset the benefits, in positive effort inducement and equality, that arise with tools such as handicapping.

The rest of this paper is structured as follows. In Section 2 we provide a theoretical benchmark of sabotage in contests. In Section 3 we outline the data relating to handicapping and interference, and in Section 4 we conduct our empirical analysis. Section 5 concludes.

\footnotetext{
Authority website http://www.britishhorseracing.com.

${ }^{4}$ Lester Piggott is the most (in)famous jockey to commit such an offense, stealing the whip of Alain Lequeux in a race in France in 1979 (The Times, November 15th 2008). He later explained that Alain 'did not seem to mind and [had] got no chance [of winning]' (The Guardian, 14th December 2003).
} 


\section{A Theoretical Benchmark}

We introduce a simple model to show how actions that are intended to reduce ex-ante efficiency difference among players may increase sabotage. We use a tournament model with sabotage similar to Lazear (1989). There are two risk-neutral players, $i$ and $j$, who compete for a prize of value $v_{i}$ and $v_{j}$ respectively. Player $i$ can either expend productive effort $e_{i}$ that improves his own probability of winning; and/or can exert destructive sabotage $s_{i}$ that reduces the effort level of their rival, and as a result the probability of their rival winning. Furthermore, Player $i$ has ability $a_{i}$ that is given exogenously. Without loss of generality assume $a_{i}>a_{j}$, i.e., Player $i$ is a-priori more efficient than Player $j$. This type of specification is common while considering 'unfair' contests and analysing the effects of asymmetry or affirmative action tools, while keeping other effects the same (see, for instance, Schotter and Weigelt (1992, pp. 517) or Gürtler and Gürtler (2015)).

Let us now denote this a-priori efficiency difference as $\triangle a=a_{i}-a_{j}$. The final output $y_{i}$ produced by player $i$ is given as

$$
y_{i}=a_{i}+e_{i}-\alpha s_{j}+\epsilon_{i}
$$

for $\alpha<1$, and $\epsilon_{i}$ is random noise. The output function is analogous for Player $j$. Exerting effort and sabotage are both costly. Consider the total cost function as:

$$
c_{i}=c\left(e_{i}, s_{i}\right)
$$

The cost function has the following properties: $c(0,0)=0, c_{1}>0, c_{11}>0, c_{2}>0$, $c_{22}>0, c_{12}>0$, ensuring a standard convex shape. ${ }^{5}$ We further assume enough convexity and Inada-type conditions that ensure the existence of an interior solution. Although we do not explicitly model possible punishment as a consequence of detected sabotage, the cost function implicitly incorporates exactly that. The convexity can imply a higher likelihood of detection with sabotage, and also a higher level of punishment.

Following the standard procedures in Tournament models, the player with the highest output wins the prize. Thus, the contest success function can be written as:

\footnotetext{
${ }^{5}$ Here a single subscript means first order partial derivative with the first or the second argument, and a double subscript means a second order own or cross partial.
} 


$$
p_{i}=\left\{\begin{array}{c}
1 \text { if } y_{i}>y_{j} \\
\frac{1}{2} \text { if } y_{i}=y_{j} \\
0 \text { if } y_{i}<y_{j}
\end{array}\right.
$$

Hence, the pay-off function for Player $i$ can be written as

$$
\begin{gathered}
\pi_{i}=p_{i} v_{i}-c\left(e_{i}, s_{i}\right) \\
=p\left(\left(a_{i}+e_{i}-\alpha s_{j}+\epsilon_{i}\right)-\left(a_{j}+e_{j}-\alpha s_{i}+\epsilon_{j}\right)>0\right) v_{i}-c\left(e_{i}, s_{i}\right) \\
=p\left(\left(\triangle a+\left(e_{i}-e_{j}\right)-\alpha\left(s_{j}-s_{i}\right)\right)>\left(\epsilon_{j}-\epsilon_{i}\right)\right) v_{i}-c\left(e_{i}, s_{i}\right) \\
=G\left(\triangle a+\left(e_{i}-e_{j}\right)-\alpha\left(s_{j}-s_{i}\right)\right) v_{i}-c\left(e_{i}, s_{i}\right)
\end{gathered}
$$

where $G($.$) is the CDF of \epsilon_{i}-\epsilon_{j}$, with unimodal PDF $g($.$) .$

Player $i$ will try to maximize payoff $\pi_{i}$ with respect to $e_{i}$ and $s_{i}$. The first order conditions are given as

$$
\begin{gathered}
\frac{\partial \pi_{i}}{\partial e_{i}}=g\left(\triangle a+\left(e_{i}-e_{j}\right)-\alpha\left(s_{j}-s_{i}\right)\right) v_{i}-\frac{\partial c}{\partial e_{i}}=0 \\
\frac{\partial \pi_{i}}{\partial s_{i}}=\alpha g\left(\triangle a+\left(e_{i}-e_{j}\right)-\alpha\left(s_{j}-s_{i}\right)\right) v_{i}-\frac{\partial c}{\partial s_{i}}=0
\end{gathered}
$$

Similarly the pay-off function for Player $j$ :

$$
\pi_{j}=\left(1-G\left(\triangle a+\left(e_{i}-e_{j}\right)-\alpha\left(s_{j}-s_{i}\right)\right)\right) v_{j}-c\left(e_{j}, s_{j}\right)
$$

And the first order conditions to maximize pay-off are:

$$
\begin{gathered}
\frac{\partial \pi_{j}}{\partial e_{j}}=g\left(\triangle a+\left(e_{i}-e_{j}\right)-\alpha\left(s_{j}-s_{i}\right)\right) v_{j}-\frac{\partial c}{\partial e_{j}}=0 \\
\frac{\partial \pi_{j}}{\partial s_{j}}=\alpha g\left(\triangle a+\left(e_{i}-e_{j}\right)-\alpha\left(s_{j}-s_{i}\right)\right) v_{j}-\frac{\partial c}{\partial s_{j}}=0
\end{gathered}
$$

From (1) and (3), we observe that $\frac{\partial c}{\partial e_{i}} / v_{i}=\frac{\partial c}{\partial e_{j}} / v_{j}$. Similarly, from (2) and (4), we obtain $\frac{\partial c}{\partial s_{i}} / v_{i}=\frac{\partial c}{\partial s_{j}} / v_{j}$ 


\section{Case 1: Symmetric Values}

If $v_{i}=v_{j}=v$, then it follows that there exists a symmetric equilibrium, with $e_{i}^{*}=e_{j}^{*}=e^{*}$ and $s_{i} *=s_{j} *=s^{*}{ }^{6}$ The above first-order conditions then simplify to

$$
g(\triangle a) v=\frac{\partial c\left(e^{*}, s^{*}\right)}{\partial e_{i}}
$$

and

$$
g(\triangle a) v=\frac{\partial c\left(e^{*}, s^{*}\right)}{\partial s_{i}} .
$$

The convexity conditions of the cost function, $c_{11}>0$ and $c_{22}>0$, then imply that both $e^{*}$ and $s^{*}$ are increasing in $g(\triangle a)$.

Recall that $\triangle a=a_{1}-a_{2}$ is the a-priori efficiency difference. In a contest it may be possible for the designer to reduce the efficiency difference either by employing handicapping (decreasing $a_{i}$ ) or by allowing head-starts (increasing $a_{j}$ ). In either case, $\triangle a$ goes down and, given the shape of the PDF, $g(\triangle a)$ increases. This results in an expected increase in equilibrium effort $e^{*}$. It is also simple to show that the probability that the most efficient player wins decreases. However, as a by-product, the contest designer is also faced with a higher level of sabotage $s^{*}$.

We have already discussed that some tools - such as handicapping - are implemented to increase equilibrium efforts. However, it is clear that it is also in the interest of players to increase their employment of sabotage when such tools are utilised. The act of sabotage is detrimental to the other players, the designer and even agents unrelated to the contest (see Chowdhury and Gürtler (2015) for a detailed discussion of this). Hence, while our model indicates that an implementation of handicapping may help to achieve certain objectives of the designer, it also increases the level of sabotage. Such sabotage may lessen or, in an extreme case, offset the benefits achieved from the original increase in productive effort.

\section{Case 2: Asymmetric Values}

Now consider the case where $v_{i} \neq v_{j}$.

Then $\frac{\partial c}{\partial e_{i}} / \frac{\partial c}{\partial e_{j}}=\frac{v_{i}}{v_{j}}$ Hence $\frac{\partial c}{\partial e_{i}} \gtrless \frac{\partial c}{\partial e_{j}}$ if $v_{i} \gtrless v_{j}$ or $e_{i} \gtrless e_{j}$ if $v_{i} \gtrless v_{j}$.

\footnotetext{
${ }^{6}$ We make additional necessary assumptions regarding the cross partial derivative $\frac{\partial^{2} c}{\partial e_{i} \partial s_{i}}$ to ensure that no other equilibrium exists.
} 
Similarly, $s_{i} \gtrless s_{j}$ if $v_{i} \gtrless v_{j}$.

This means that irrespective of the efficiency, the player with the higher value expends more effort as well as more sabotage in the equilibrium.

Now, let us consider the case when handicapping takes place, i.e. $\triangle a=a_{i}-a_{j}$ goes down. Recall Equation 1: $g\left(\triangle a+\left(e_{i}-e_{j}\right)-\alpha\left(s_{j}-s_{i}\right)\right) v_{i}=\frac{\partial c}{\partial e_{i}}$. Assume, without loss of generality, that $v_{i}>v_{j}$. Then $e_{i}^{*}>e_{j}^{*}$, and as a result $c\left(e_{i}^{*}\right)>c\left(e_{j}^{*}\right)$ and $c\left(s_{i}^{*}\right)>c\left(s_{j}^{*}\right)$. So when $\triangle a$ decreases by the same amount for both the players, both the effort as well as the sabotage exerted by both players will increase. However, as less effort or sabotage is needed to increase the same amount of cost for player $i$ than player $j$ (due to convexity), the increase in effort and sabotage by player $i$ will be less than the increase in effort and sabotage by player $j$.

Hence, the main result, that players exert more effort and sabotage as a result of handicapping, remains the same even in the asymmetric version of the model, and the ex-ante efficiency difference does not matter here. The increase in sabotage due to handicapping, by the player with the higher value for the prize, is less than the increase in sabotage due to handicapping by the player with the lower value for the prize. This is because the marginal cost over the marginal benefit of exerting sabotage is not as great as for the player with the lower valuation. In horse racing, where the horse-jockey combination with higher efficiency often also has the higher value of the prize, we should expect a weaker horse to increase sabotage by more than a stronger horse. However, this is difficult to test in our data because we cannot identify the strength of horses prior to handicapping; we only have betting odds after the handicapping has taken place.

Nevertheless, in the next two sections we will test our main hypothesis that handicapping leads to greater sabotage.

\section{Data}

We obtained data on 19,635 U.K. horse races in 2011 and 2012 from Betwise (www.betwise.co.uk), a betting information company. This data include information on the time and date of each race, the class of the race (which ranges from 1 (top) to 7 (bottom)), the number of horses 
in each race, the prize money on offer to the winner, and the distance over which the race is run. In addition, we have the type of race (e.g. flat - i.e., a standard race, and jump - i.e., a hurdle race or steeplechase) and whether or not the race was a handicap.

A slim majority $(59.9 \%)$ of the races in our sample are handicap races. The regulatory body in charge of horse racing, and indeed the racecourses, have to balance two elements when deciding whether to schedule handicap or non-handicap races. On the one hand, bettors are interested in the type of close races that are facilitated by handicapping, as uncertainty creates an additional skill level to betting. On the other hand, fans of horse racing are keen to see the best horses run unencumbered, at their full potential. As a result, only $38 \%$ of class 1 and 2 races in our sample, where the best horses participate, are handicaps. Nevertheless, almost all (99.5\%) race meetings will have at least 1 handicap race in its schedule. This means that the majority of jockeys in our sample (60.9\%) perform, at some point or another, in both handicap races and non-handicap races. In our later analysis, we will exploit this 'within-subject' variation in the propensity to sabotage.

Supplementing our race data, we have information on each of the horses competing. This includes the age of the horse, and also the bookmaker odds at the time the race begins, otherwise known as the starting price. Summary statistics on race and horse data can be found in Table 1. As expected, the standard deviation of the implied win probability (calculated from the starting price) is larger for non-handicap races than for handicap races. This reflects the fact that without handicapping, certain horses have very little chance of winning.

[Insert Table 1 here]

We also require data related to interference. The BHA entrust multiple race stewards to investigate and punish cases of interference. Information on all stewards' enquiries relating to interference can be found on the BHA webpage. ${ }^{7}$ Details of the procedures followed by the stewards can be found in BHA Manual B Schedule 6. Below is a typical example of the

\footnotetext{
${ }^{7}$ www.britishhorseracing.com/resources/about/whatwedo/disciplinary/stewardsEnquiries.asp.
} 
output displayed after an enquiry, in this case from a race at Towcester on 10th January 2011.

'The Stewards held an enquiry into possible interference approaching the final flight. They found that the winner, BADGERS COVE (IRE) ridden by Charlie Poste, had interfered with OVERNIGHT FAME, ridden by Denis O'Regan, placed second. They found Poste in breach of Rule (B)54.1 and guilty of careless riding in that he allowed his mount to drift to the right. They suspended him for 2 days as follows: Monday, 24th and Tuesday, 25th January 2011.

If we assume handicap races are more competitive, horses will spend more time in close proximity to each other in these races. We are therefore keen to distinguish between cases of accidental interference (which may occur as a result of this proximity) and intentional interference. The BHA procedures allow us to do precisely that. Consider the following case of accidental interference from a race at Wolverhampton also on 10th January 2011. Such cases are not classified as sabotage in our data-set. ${ }^{8}$

'The Stewards noted that DAUNTSEY PARK (IRE), unplaced, had interfered with the winner, BLACK COFFEE, at approximately five furlongs out, but after viewing a video recording of the incident, they were satisfied that it was caused by accident. They therefore took no further action:

We married the data on guilty interference with the race and horse data described in Table 1. We only analysed data from racetracks with at least one incident of interference over the two year sample. This was to ensure that racetracks outside of the BHA's jurisdiction, or racetracks with overly lenient stewards, did not cloud our analysis. We lose $25 \%$ of the data as a result of excluding racetracks with no sabotage. Racetracks with no sabotage (in our sample) predominantly play host to low grade, amateur racing. Amongst our remaining observations, there were 1,099 cases of interference, of which 787 occurred in handicap races. $0.46 \%$ of competitors were guilty of interference in non-handicap races, but this rises to $0.68 \%$ for handicap races. In the following section, we present our more formal analysis. For clarity, we will now refer to interference as sabotage.

\footnotetext{
${ }^{8}$ Accidental interference is indeed slightly more common in handicap races than non-handicap races. This, we assume, is partly due to the aforementioned proximity of competitors in handicap races.
} 


\section{Analysis}

\subsection{Handicapping and Sabotage}

The outcomes of handicap races are more uncertain than non-handicap races. Reflecting the uncertainty created by handicapping, the favourite wins $41.43 \%$ of non-handicap races in our sample, but only $27.5 \%$ of handicap races. Regression analysis, not displayed in the paper for space reasons, also supports the view that handicapping is effective in levelling the field. Having stated these findings, we now proceed to our main hypothesis.

Hypothesis 1. Sabotage is employed more in a handicap contest compared to a nonhandicap contest.

To test this hypothesis, in Table 2 we present two logit regressions relating to sabotage. These regressions incorporate each horse performance, and consider horse-specific variables such as age and implied win probability, rather than considering only race features. We therefore cluster standard errors at the race-level. In Regression 1, an indicator variable, equalling 1 if the jockey was a saboteur and 0 otherwise, is regressed on an indicator variable equalling 1 if the horse was racing in a handicap race. The relationship is positive and significant (at the $0.1 \%$ level). In Regression 2, we include control variables. Once again, the relationship is positive and significant (at the $0.1 \%$ level), and gives an odds ratio of 1.57 of sabotage in a handicap race relative to a non-handicap race. In other words, destructive effort is clearly more prevalent in handicap contests relative to non-handicap contests.

A closer look at our control variables also reveals that sabotage is more of an issue in shorter races, increases with prize money (though much of this effect is captured by the class of the race), is often carried out by horses in the prime of their careers (witness the concave relationship between horse age and the propensity to engage in sabotage), and is predominantly carried out by horses/jockeys with a good chance of victory (implied win probability is positive and significant). ${ }^{9}$ However, most of these effects have weaker statistical

\footnotetext{
${ }^{9}$ It could be argued that heavily favoured horses are favoured, in part, because they engage in sabotage. In other words, the betting market anticipates that a given competitor is likely to use sabotage and revises their pre-race win probability accordingly. Contrary to this argument, later in our study we analyse the effect
} 
significance than the effect of handicapping. It is interesting to observe that sabotage occurs more often, even after controlling for other factors, in flat races.

[Insert Table 2 here]

One problem with our empirical set-up is that jockeys are not randomly assigned across races. There may therefore be a selection of jockeys with a propensity for sabotage into handicap races. As noted earlier however, the majority (60.9\%) of jockeys perform in both types of races. This allows us to explore within-subject variation in the propensity to sabotage. In other words, is a given jockey more likely to sabotage a competitor in a close handicap race than a more uneven non-handicap race? In Table 3, we replicate the Table 2 analysis, but this time include jockey fixed effects. The downside to this latest analysis is that we lose $21.1 \%$ of observations: any jockey that only commits sabotage in a handicap/non-handicap race is necessarily excluded from the sample.

In Regression 1, an indicator variable, equalling 1 if the jockey was a saboteur and 0 otherwise, is regressed on an indicator variable equalling 1 if the horse was racing in a handicap race. The size of the handicap coefficient declines with the inclusion of jockey fixed effects, but remains positive and significant (at the $0.1 \%$ level). In Regression 2 we add the control variables from earlier. Interestingly, many of the race variables - such as the indicator for jump racing and the distance of the race - decline in significance after the inclusion of jockey fixed effects. However, the handicap indicator remains significant, suggesting that a given jockey is more likely to commit sabotage in a handicap race than a non-handicap race.

\section{[Insert Table 3 here]}

Our next set of analysis is intended to hone in on the mechanism behind this main result. Are handicap races afflicted by more sabotage due to the evenness of the competitors, as of sabotage on wins and finishing positions, and our results suggest that acts of sabotage - and the gains that accrue to the saboteur - are not fully anticipated by the betting market. These results can be found in Table 5, and Figures 1 and 2. 
the model in Section 2 suggests? Importantly, handicap races will differ in their closeness, depending, amongst other things, on the competence of the handicapper. If the handicapper does a poor job, or if important information on the quality of horses arrives after the weights are decided, horses will go off at vastly different odds. Similarly, certain non-handicap races may be very closely matched without a handicapper's intervention. To get closer to establishing that handicapping drives sabotage, we should examine whether close races - both of the handicap and non-handicap variety - attract more sabotage than less close races.

Our ex-ante measure of the closeness of the race is the standard deviation of implied win probability. In Regression 1 of Table 4, we regress our saboteur indicator on this standard deviation plus the other control variables used in Tables 2 and 3 (including the handicap indicator). As expected, we find that sabotage is indeed more prevalent in close contests (i.e. when the standard deviation of implied win probability in the race is low). However, the handicap indicator does remain positive and significant after the inclusion of the standard deviation of implied win probability, suggesting that handicapping has a direct impact on the prevalence of sabotage. Nevertheless, the coefficient is diminished in comparison to Table 2 (0.329 compared to 0.453$)$, suggesting that handicap races are afflicted by greater sabotage, at least in part, because they are closer races.

In our next set of regressions we want to examine whether close races, either handicap or non-handicap, attract more sabotage than less close races. In Regressions 2 and 3 of Table 4 we therefore exclude the handicap race indicator and instead regress our saboteur indicator on the remaining variables, but this time for sub-samples of handicap and nonhandicap races. In Regression 2 we find that there is a greater prevalence of sabotage in close handicap contests (compared to less close handicap contests) with significance at the 5\% level. In Regression 3 we find that close non-handicap races are also afflicted by higher levels of sabotage than less close non-handicap contests (with significance at the $1 \%$ level). In other words, the closer the race ex-ante, the more likely we are to observe sabotage, regardless of whether the race is a handicap or not. This result gives us greater confidence that the closeness created by handicapping is at least partially responsible for the higher levels of sabotage in those races. 
[Insert Table 4 here]

There is an alternative explanation for our results. It is possible that stewards are simply more vigilant in detecting and punishing sabotage in handicap races than they are in nonhandicap races. This may be because stewards expect sabotage to take place in close races, or because they keep a keener eye on such incidents because sabotage is more likely to affect the race outcome. The implication is that we may be over-estimating the effect of handicapping on the propensity to sabotage. Unfortunately, this is not an alternative explanation that we can exclude with the data, as we are forced to work under the assumption that detection efforts are uniform across races.

\subsection{Sabotage and Contest Outcomes}

Our final aim in this study is to quantify the effect of sabotage on contest outcomes. It is one aspect to establish that handicap contests are more susceptible to sabotage, but whether this destructive practice actually works in the saboteur's favour is still not clear. From a theoretical point of view, it is simple to show that, ceteris paribas, a participant's win probability increases when a player exerts sabotage effort compared to when he or she does not. We test the success of sabotage in our next hypothesis:

Hypothesis 2. Employment of sabotage improves the performance of the saboteur in contests.

One issue in testing this hypothesis is that the finishing position of each horse, in the Betwise data, is classified after any stewards' enquiry has taken place. It is possible, therefore, that a horse finished first after an act of sabotage, but was demoted to second place after the stewards' enquiry. In our data, this horse would be listed as finishing second. Fortunately, such cases are quite rare. Reading through the BHA documentation (see page 14 of the BHA Guide to Procedures 2009), and the reports of the stewards' enquiries, we get the impression that the stewards are discouraged from changing the final classification of races. This is primarily because the counterfactual - where the horse would have finished if not for the act of sabotage - is unobservable and difficult to predict. Moreover, with large sums sometimes 
staked on the outcome of these races, any arbitrary re-classification of finishing positions is likely to prove controversial with bettors. Our impression from reading the reports is that stewards seek to deter sabotage by suspending jockeys from future meetings, rather than retrospectively amending the outcome of races.

In Panel $\mathrm{A}$ of Table 5 we regress an indicator variable equalling 1 if the jockey won the race (as classified in the Betwise data), and 0 otherwise, on an indicator variable equalling 1 if the jockey was a saboteur, and on the implied win probability of the horse (as inferred from the starting price). We find that sabotage does indeed improve the saboteur's chances of victory (significant at the $0.1 \%$ level) relative to the betting market's pre-race expectations. The coefficient associated with the saboteur indicator variable implies an odds ratio of 2.95 of a saboteur winning the race relative to a non-saboteur with the same pre-race prospects. This result is most vividly captured in Figure 1 . We plot the average win indicator (i.e. the win frequency) for saboteurs, victims and uninvolved third parties. Compared to the implied win probabilities, and using third parties as a reference point, saboteurs win more often than their pre-race odds would suggest, while the prospects of victims are clearly hampered by the saboteur's actions. This is particularly apparent for lower implied win probabilities, where there are more observations and where much of the noise is averaged out. This result is particularly striking given that a few saboteurs may have had their positions downgraded after a stewards' enquiry.

\section{[Insert Table 5 here]}

In the remainder of Panel $\mathrm{A}$ we examine whether the effect is more pronounced in handicap/non-handicap/jump and flat races. While sabotage is, initially, more likely to be effective in handicap contests as the races are close, we would expect competitors to use sabotage in both types of contests until the marginal impact is equal across each type of race. Indeed, this appears to be the case as the coefficients across handicap and non-handicap races are similar. The effect of sabotage on the saboteur's win prospects are higher, however, in jump races compared to flat races, suggesting that there are some unexploited opportunities for sabotage in the former. 
[Insert Figure 1 here]

One problem with our initial choice of performance measure (whether the horse won the race), is that the out-performance of the saboteur could be confounded with the wellknown favourite-longshot bias. This is the empirical regularity - dating from Griffith (1949) - that the returns to betting on favourites exceed the returns to betting on longshots. ${ }^{10}$. This means that favourites (longshots) will win more (less) often than their odds suggest. As saboteurs are disproportionately favoured horses (see Table 2), the favourite-longshot bias could generate the results in the top panel of Table 6 without sabotage actually being beneficial for the saboteur.

To circumvent this issue we also used the following measure of performance used by Brown (2012):

$$
\text { Performance }=\frac{\text { PredictedFinishingPosition }- \text { ActualFinishingPosition }}{\text { Numberof HorsesinRace }}
$$

The predicted finishing position is constructed by ordering the horses in each race by their odds. Those with the shortest odds are predicted to finish first, those with the second shortest odds are predicted to finish second, and so on. If Performance is negative, the horse has underperformed, while a positive Performance signals out-performance. This measure allows us to capture the effect of sabotage on the full spectrum of horses, unlike the previous specification which focused only on the identity of one horse (the winner). This measure also has a negative bias when it comes to favoured horses. For example, a horse predicted to finish first can only under-perform (vice versa, a horse predicted to finish last can only outperform). Therefore, in each of the following regressions we control for the predicted percentile of the horse. For example, a horse predicted to finish 4th out of 14 horses would have a predicted percentile of $100 *(4 / 14)=28.57 t h$.

From Panel B of Table 5 we can see that the saboteur does indeed gain places (significant at the $0.1 \%$ level). Judging by the size of the coefficients - and the average number of

\footnotetext{
${ }^{10}$ See Ottaviani and Sørensen (2008) for a survey of the explanations for the bias.
} 
horses in each race (see Table 1) - the saboteur finishes, on average, 1.43 positions higher than betting market expectations as a result of their actions. We also replicate this analysis for handicap/non-handicap/jump and flat race sub-samples. The overall result is captured in Figure 2, where we average the performance measure for saboteurs, victims and third parties for each predicted percentile (rounded to the nearest whole number) across the full sample. Saboteurs significantly outperform expectations, while victims suffer relative to pre-race expectations. This positional gain explains why saboteurs sabotage.

[Insert Figure 2 here]

\section{Conclusion}

Contests are a family of games where players make costly sunk investments in order to win rewards. There are very many situations in the field in which contests are employed to select winners for rewards. Tools such as handicapping, head-starts, caps on effort etc. are often used in political and economic contests, sometimes for ethical reasons (e.g. in affirmative actions), but also to increase the aggregate effort of unevenly able participants. The existing literature show that these tools, in general, are capable of achieving the objectives of the designer.

In this paper we introduce, for the first time, analyses of sabotage behaviour in contests that use a handicapping tool to level the playing field. We show theoretically that implementation of such policies indeed increases equilibrium effort. However, as a by-product, incidences of sabotage also increase. We utilise a unique data set from the British horse racing industry to empirically verify this second prediction. We demonstrate that participants indeed display a greater propensity for destructive acts in contests where handicapping is implemented.

It has previously been shown that effort, particularly from weaker participants, is higher in even contests (see, for example, Che and Gale (1998)). Studies such as Tsoulouhas et al. (2007) argue against such policies - common in workplace environments (Pfeifer (2011)) - as 
they may reduce the ability of the future players in a repeated setting. However, our results shed light on the possible harmful effects of levelling the contest even in a static setting, as it appears to incentivize sabotage.

Our results are of particular interest in settings such as workplaces, political campaigns, and sports, in which it is possible for players to sabotage rivals. (Contests in which players cannot access their rivals - e.g. applications to colleges, innovation tournaments etc. - will be safe from the implications of our results). This means that capping campaign budgets in political races, handicapping 'superstar' workers in internal labour markets, or giving headstarts to local companies may even result in lower welfare than the status-quo. ${ }^{11}$ As there are both benefits, in terms of higher effort, and damage - in terms of sabotage - in levelling the playing field, our results also suggest that an optimal level of handicapping could be chosen to elicit the highest net constructive effort in a contest.

\footnotetext{
${ }^{11}$ Several designs popularly used to reduce sabotage (see Chowdhury and Gürtler (2015)) are not necessarily employable in every setting. Sabotage might be reduced by introducing detection procedure and punishments, but these also incur individual and social costs.
} 


\section{References}

- Amegashie, J., A., Runkel, M., (2007). Sabotaging Potential Rivals. Social Choice and Welfare, 28, 143-162.

- Balafoutas, L., Sutter, M., (2012). Affirmative Action Policies Promote Women and Do Not Harm Efficiency in the Laboratory. Science, 335, 579-582.

- Balafoutas, L., Lindner, F., Sutter, M., (2012). Sabotage in Tournaments: Evidence from a Natural Experiment. Kyklos, 65, 425-441.

- Baye, M., Kovenock, D., and de Vries, C., (1993). Rigging the Lobbying Process: An Application of the All-Pay Auction. American Economic Review, 83, 289-294.

- Brown, A., (2012). Examining Agency Conflict in Horse Racing. Southern Economic Journal, 79, 388-398.

- Brown, J., (2011). Quitters Never Win: The (Adverse) Incentive Effects of Competing with Superstars. Journal of Political Economy, 119, 982-1013.

- Calsamiglia, C., Franke, J., and Rey-Biel, P., (2013). The Incentive Effects of Affirmative Action in a Real-Effort Tournament. Journal of Public Economics, 98, 15-31.

- Carpenter, J., Matthews, P., H., Schirm, J., (2010). Tournaments and Office Politics: Evidence from a Real Effort Experiment. American Economic Review, 100, 504-517.

- Chan, W., (1996). External Recruitment versus Internal Promotion. Journal of Labor Economics, 14, 555-570.

- Che, Y., K., Gale, I., (1998). Caps on Political Lobbying. American Economic Review, $88,643-651$.

- Chen, K., P., (2003). Sabotage in Promotion Tournaments. Journal of Law, Economics and Organisation, 19, 119-140.

- Chowdhury, S., M., Gürtler, O., (2015). Sabotage in Contests: A Survey. Public Choice, 164 (1), 135-155. 
- Coffey, B., Maloney, M., T., (2010). The Thrill of Victory: Measuring the Incentive to Win. Journal of Labor Economics, 28, 87-112.

- del Corral, J., Prieto-Rodrigeuz, J., Simmons, R., (2010). The Effect of Incentives on Sabotage: The Case of Spanish Football. Journal of Sports Economics, 11, 243-260.

- Dechenaux, E., Kovenock, D., Sheremeta, R., M., (2015). A Survey of Experimental Research on Contests, All-Pay Auctions and Tournaments, Experimental Economics, 18, 609-669.

- Deutscher, C., Frick, B., Gürtler, O., Prinz, J., (2013). Sabotage In Tournaments with Heterogeneous Contestants: Empirical Evidence from the Soccer Pitch. Scandinavian Journal of Economics, 115, 1138-1157.

- Fallucchi, F., Quercia, S., (2016). Affirmative Action and Retaliation in Experimental Contests. (No. 16-03). CBESS Working Paper Series (No. 16-03).

- Fort, R., Maxcy J., (2003). Competitive Balance in Sports Leagues: An Introduction. Journal of Sports Economics, 4, 154-160.

- Franke, J., (2012a). Affirmative Action in Contest Games. European Journal of Political Economy, 28, 105-118.

- Franke, J., (2012b). The Incentive Effects of Levelling the Playing Field - An Empirical Analysis of Amateur Golf Tournaments, Applied Economics, 44, 1193-1200.

- Fryer R.,J., and Loury, G.,C., (2005). Affirmative Action in Winner-Take-All Markets. Journal of Economic Inequality, 3, 263-280.

- Fu, Q., (2006). A Theory of Affirmative Action in College Admissions, Economic Inquiry, 44, 420-428.

- Garicano, L., Palacios-Huerta, I., (2014). Sabotage in Tournaments: Making the Beautiful Game a Bit Less Beautiful, in Beautiful Game Theory, Princeton University Press.

- Girard, V., (2016). Don't Touch My Road. Evidence from India on Affirmative Action and Everyday Discrimination. Mimeo. 
- Griffith, R., M., (1949). Odds Adjustments by American Horse-Racing Bettors. American Journal of Psychology, 62, 290-294.

- Gürtler, O., Münster, J., (2010). Sabotage in Dynamic Tournaments. Journal of Mathematical Economics, 46, 179-190.

- Gürtler, M., Gürtler, O., (2015). The optimality of heterogeneous tournaments. Journal of Labor Economics, 33, forthcoming.

- Harbring, C., Irlenbusch, B., Kräkel, M., Selten, R., (2007). Sabotage in Corporate Contests - An Experimental Analysis. International Journal of the Economics of Business, 14, 367-392.

- Harbring, C., Irlenbusch, B., (2008). How Many Winners are Good to Have? On Tournaments with Sabotage. Journal of Economic Behavior and Organisation, 65, 682-702.

- Kirkegaard, R., (2012). Favoritism in Asymmetric Contests: Head Starts and Handicaps. Games and Economic Behavior, 76, 226-248.

- Konrad, K., A., (2000). Sabotage in Rent-Seeking Contests. Journal of Law, Economics and Organisation, 16, 155-165.

- Konrad, K., A., (2009). Strategy and Dynamics in Contests: London School of Economics Perspectives in Economic Analysis. Oxford University Press.

- Kräkel, M., (2005). Helping and Sabotaging in Tournaments. International Game Theory Review, 7, 211-228.

- Lazear, E., P., (1989). Pay Equality and Industrial Politics. Journal of Political Economy, $97,561-580$.

- Lazear, E., P., Rosen, S., (1981). Rank Order Tournaments as Optimum Labor Contracts. Journal of Political Economy, 89, 841-864. 
- Leibbrandt, A., Wang, L., C., Foo, C., (2015). Gender Quotas, Competitions, and Peer Review: Experimental Evidence on the Backlash Against Women. CESIFO Working paper (No. 5526).

- Lynch, J., G., (2005). The Effort Effects of Prizes in the Second Half of Tournaments. Journal of Economic Behavior and Organization, 57, 115-129.

- Münster, J., (2007). Selection Tournaments, Sabotage and Participation. Journal of Economics and Management Strategy, 16, 943-970.

- Niederle, M., Segal, C., Vesterlund, L. (2013). How Costly is Diversity? Affirmative Action in Light of Gender Differences in Competitiveness. Management Science, 59, $1-16$.

- Ottaviani, M., Sørensen, P., N., (2008), The Favorite-Longshot Bias: An Overview of the Main Explanations. Handbook of Sports and Lottery Markets, North Holland, edited by Hausch, D., B., Ziemba, W., T., 83-101.

- Pfeifer, C., (2011). Handicaps in Job Assignment: Insiders, Outsiders and Gender. Journal of Labor Research, 32, 1-20.

- Runkel, M., (2006). Optimal Contest Design, Closeness and the Contest Success Function. Public Choice, 129, 217-231.

- Salop, S.,C., Scheffman, D., T., (1983). Raising Rivals' Costs. The American Economic Review, 73, 267-271.

- Schotter, A., Weigelt, K. (1992). Asymmetric Tournaments, Equal Opportunity Laws, and Affirmative Action: Some Experimental Results, Quarterly Journal of Economics, $107,511-539$.

- Skaperdas, S., and Grofman, B., (1995). Modeling Negative Campaigning. American Political Science Review, 89, 49-61.

- Soubeyran, R., (2009). Contest with Attack and Defense: Does Negative Campaigning Increase or Decrease Voter Turnout? Social Choice and Welfare, 32, 337-353. 
- Sunde, U., (2009). Heterogeneity and Performance in Tournaments: A Test for Incentive Effects Using Professional Tennis Data. Applied Economics, 41, 3199-3208.

- Szymanski, S., (2003). The Economic Design of Sporting Contests. Journal of Economic Literature, 41, 1137-1187.

- Tsoulouhas, T., Knoeber, C., R., Agrawal, A., (2007). Contests to Become CEO: Incentives, Selection and Handicaps. Economic Theory, 30, 195-221. 


\section{Tables}

\begin{tabular}{|c|c|c|c|c|c|}
\hline Table 1. Summary Statistics & 1 & 2 & 3 & 4 & 5 \\
\hline Races & All $(\mathrm{N}=19,635)$ & Hcap $(\mathrm{N}=11,766)$ & Non Hcap $(\mathrm{N}=7,869)$ & Jump $(\mathrm{N}=6,631)$ & Flat $(\mathrm{N}=13,004)$ \\
\hline \multirow[t]{2}{*}{ No. of Runners } & 9.332 & 9.793 & 8.642 & 8.811 & 9.598 \\
\hline & $(3.448)$ & $(3.427)$ & $(3.363)$ & $(3.586)$ & $(3.345)$ \\
\hline \multirow[t]{2}{*}{ Win Prize Money (000s of GBP) } & 9.661 & 7.395 & 13.048 & 9.102 & 9.946 \\
\hline & $(33.85)$ & $(17.341)$ & $(48.899)$ & $(26.318)$ & $(37.109)$ \\
\hline \multirow[t]{2}{*}{ Distance (000s of yards) } & 2.748 & 2.766 & 2.72 & 4.443 & 1.884 \\
\hline & $(1.407)$ & $(1.436)$ & $(1.362)$ & $(.751)$ & $(.7)$ \\
\hline Horse Runs & All $(\mathrm{N}=183,046)$ & Hcap $(\mathrm{N}=115,023)$ & Non Hcap $(\mathrm{N}=68,023)$ & Jump $(\mathrm{N}=58,417)$ & Flat $(\mathrm{N}=124,629)$ \\
\hline \multirow[t]{2}{*}{ Age (Years) } & 4.995 & 5.453 & 4.218 & 6.877 & 4.112 \\
\hline & $(2.3)$ & $(2.288)$ & $(2.103)$ & $(2.018)$ & $(1.849)$ \\
\hline \multirow[t]{2}{*}{ Implied Win Probability } & 0.123 & 0.118 & 0.132 & 0.129 & 0.12 \\
\hline & $(.114)$ & $(.089)$ & $(.147)$ & $(.124)$ & $(.109)$ \\
\hline
\end{tabular}

Summary statistics for 19,635 horse races in the U.K. in 2011 and 2012 . Column 1 encompasses the full sample, with sub-samples relating to

handicap races, non-handicap races, jump races, and flat races in columns 2, 3, 4 and 5 respectively. The top panel focuses on race statistics with individual horse statistics in the bottom panel. The main measure is the mean, with standard deviations in parentheses. Implied Win Probability is calculated as $1 /(\mathrm{SP}+1)$ where $\mathrm{SP}$ is the starting price odds (a summary measure of British bookmaking odds at the start of the race). 


\begin{tabular}{|c|c|c|}
\hline Table 2. Sabotage & & \\
\hline Dependent Variable: Saboteur & All & All \\
\hline Intercept & $\begin{array}{c}-5.38^{* * *} \\
(.058)\end{array}$ & $\begin{array}{c}-5.65^{* * *} \\
(.203)\end{array}$ \\
\hline Handicap Race & $\begin{array}{c}0.402^{* * *} \\
(.068)\end{array}$ & $\begin{array}{c}0.453^{* * *} \\
(.076)\end{array}$ \\
\hline Jump Race & & $\begin{array}{c}-0.999 * * * \\
(.148)\end{array}$ \\
\hline Top Class Race & & $\begin{array}{l}0.31^{* *} \\
(.105)\end{array}$ \\
\hline No. of Runners & & $\begin{array}{l}0.011 \\
(.008)\end{array}$ \\
\hline Win Prize Money (000s of GBP) & & $\begin{array}{l}0.0002 \\
(.0008)\end{array}$ \\
\hline Distance (000s of yards) & & $\begin{array}{c}-0.125^{* *} \\
(.045)\end{array}$ \\
\hline Age & & $\begin{array}{l}0.083 \\
(.075)\end{array}$ \\
\hline$A g e^{2}$ & & $\begin{array}{l}-0.006 \\
(.006)\end{array}$ \\
\hline Implied Win Probability & & $\begin{array}{c}2.628^{* * *} \\
(.196)\end{array}$ \\
\hline No. of Clusters (Races) & 19,635 & 19,635 \\
\hline No. of Obs. where Dep. Var. $=1$ & 1,099 & 1,099 \\
\hline No. of Obs. & 183,046 & 183,046 \\
\hline Pseudo $R^{2}$ & 0.0028 & 0.031 \\
\hline
\end{tabular}

Coefficient estimates when an indicator variable equalling 1 if the jockey was guilty of sabotage, and 0 otherwise, was regressed on an indicator variable equalling 1 if the horse was racing in a handicap race, and 0 otherwise. A logit specification was used and control variables were added in regression 2. (Races of class 1 or 2 are designated as top class). Heteroskedasticity-consistent standard errors (clustered at the race level) are in parentheses and $* * *, * *, *$, and indicates significance at the $0.1 \%, 1 \%, 5 \%$, and $10 \%$ level respectively. 


\begin{tabular}{|c|c|c|}
\hline Dependent Variable: Saboteur & All & All \\
\hline Handicap Race & $\begin{array}{c}0.282^{* * *} \\
(.069)\end{array}$ & $\begin{array}{c}0.383^{* * *} \\
(.078)\end{array}$ \\
\hline Jump Race & & $\begin{array}{c}-0.413 . \\
(.241)\end{array}$ \\
\hline Top Class Race & & $\begin{array}{c}0.409^{* *} \\
(.108)\end{array}$ \\
\hline No. of Runners & & $\begin{array}{l}0.013 \\
(.009)\end{array}$ \\
\hline Win Prize Money (000s of GBP) & & $\begin{array}{l}0.0002 \\
(.0008)\end{array}$ \\
\hline Distance (000s of yards) & & $\begin{array}{l}-0.05 \\
(.051)\end{array}$ \\
\hline Age & & $\begin{array}{c}0.06 \\
(.072)\end{array}$ \\
\hline$A g e^{2}$ & & $\begin{array}{l}-0.007 \\
(.006)\end{array}$ \\
\hline Implied Win Probability & & $\begin{array}{l}2.8^{* * *} \\
(.243)\end{array}$ \\
\hline Jockey Fixed Effects & Yes & Yes \\
\hline No. of Clusters (Jockeys) & 328 & 328 \\
\hline No. of Obs. & 144,452 & 144,452 \\
\hline
\end{tabular}

Coefficient estimates when an indicator variable equalling 1 if the jockey was guilty of sabotage, and 0 otherwise, was regressed on an indicator variable equalling 1 if the horse was racing in a handicap race, and 0 otherwise. Jockey fixed effects are included in these regressions. A logit specification was used and control variables were added in regression 2. (Races of class 1 or 2 are designated as top class). Heteroskedasticityconsistent standard errors (clustered at the jockey level) are in parentheses and ${ }^{* * *},{ }^{* *},{ }^{*}$, and . indicates significance at the $0.1 \%, 1 \%, 5 \%$, and $10 \%$ level respectively. 


\begin{tabular}{|c|c|c|c|}
\hline \multicolumn{4}{|l|}{ Table 4. Sabotage: Further Analysis } \\
\hline Dependent Variable: Saboteur & All & Handicap & Non-Handicap \\
\hline \multirow[t]{2}{*}{ Intercept } & $-5.193^{* * *}$ & $-5.35^{* * *}$ & $-4.113^{* * *}$ \\
\hline & $(.251)$ & $(.334)$ & $(.391)$ \\
\hline \multirow[t]{2}{*}{ Std. Dev. of IWP in Race } & $-2.845^{* *}$ & $-2.931^{*}$ & $-3.767^{* *}$ \\
\hline & $(.977)$ & $(1.491)$ & $(1.342)$ \\
\hline \multirow[t]{2}{*}{ Handicap Race } & $0.329^{* * *}$ & & \\
\hline & $(.086)$ & & \\
\hline \multirow[t]{2}{*}{ Jump Race } & $-0.991^{* * *}$ & $-1.457^{* * *}$ & -0.232 \\
\hline & $(.149)$ & $(.194)$ & $(.246)$ \\
\hline \multirow[t]{2}{*}{ Top Class Race } & $0.287^{* *}$ & $0.281^{*}$ & 0.264 \\
\hline & $(.104)$ & $(.136)$ & $(.169)$ \\
\hline \multirow[t]{2}{*}{ No. of Runners } & -0.002 & 0.018 & $-0.047^{*}$ \\
\hline & $(.009)$ & $(.012)$ & $(.019)$ \\
\hline \multirow[t]{2}{*}{ Win Prize Money (000s of GBP) } & 0.0003 & -0.001 & 0.0008 \\
\hline & $(.0008)$ & $(.002)$ & $(.0008)$ \\
\hline \multirow[t]{2}{*}{ Distance (000s of yards) } & $-0.12^{* *}$ & -0.021 & $-0.29 * *$ \\
\hline & $(.045)$ & $(.053)$ & $(.094)$ \\
\hline \multirow[t]{2}{*}{ Age } & 0.083 & 0.102 & -0.041 \\
\hline & $(.075)$ & $(.099)$ & $(.119)$ \\
\hline \multirow[t]{2}{*}{$A g e^{2}$} & -0.006 & -0.009 & 0.01 \\
\hline & $(.006)$ & $(.009)$ & $(.01)$ \\
\hline \multirow[t]{2}{*}{ Implied Win Probability } & $2.911^{* * *}$ & $3.639^{* * *}$ & $2.282^{* * *}$ \\
\hline & $(.24)$ & $(.365)$ & $(.321)$ \\
\hline No. of Clusters (Races) & 19,635 & 11,766 & 7,869 \\
\hline No. of Obs. where Dep. Var.=1 & 1,099 & 787 & 312 \\
\hline No. of Obs. & 183,046 & 115,023 & 68,023 \\
\hline Pseudo $R^{2}$ & 0.0317 & 0.0338 & 0.0277 \\
\hline
\end{tabular}

Coefficient estimates when an indicator variable equalling 1 if the jockey was guilty of sabotage, and 0 otherwise, was regressed on the standard deviation of implied win probability within the race and the control variables from Table 2. In the second and third regressions we break the sample down into handicap and non-handicap races respectively. A logit specification was used, heteroskedasticity-consistent standard errors (clustered at the race level) are in parentheses, and ${ }^{* * *}, * *, *$, and . indicates significance at the $0.1 \%, 1 \%$, $5 \%$, and $10 \%$ level respectively. 


\begin{tabular}{|c|c|c|c|c|c|}
\hline Table 5: Effect of Sabotage & & & & & \\
\hline \multicolumn{6}{|l|}{ Panel A: Wins } \\
\hline Dependent Variable: Winner & All & Hcap & Non Hcap & Jump & Flat \\
\hline Intercept & $\begin{array}{c}-3.267^{* * *} \\
(.011)\end{array}$ & $\begin{array}{c}-3.29^{* * *} \\
(.015)\end{array}$ & $\begin{array}{c}-3.347^{* * *} \\
(.018)\end{array}$ & $\begin{array}{c}-3.256^{* * *} \\
(.019)\end{array}$ & $\begin{array}{c}-3.275^{* * *} \\
(.0138)\end{array}$ \\
\hline Saboteur & $\begin{array}{c}1.08^{* * *} \\
(.077)\end{array}$ & $\begin{array}{c}1.018^{* * *} \\
(.093)\end{array}$ & $\begin{array}{c}1.181^{* * *} \\
(.145)\end{array}$ & $\begin{array}{c}1.5^{* * *} \\
(.201)\end{array}$ & $\begin{array}{c}1.016^{* * *} \\
(.084)\end{array}$ \\
\hline Implied Win Probability & $\begin{array}{c}7.115^{* * *} \\
(.06)\end{array}$ & $\begin{array}{c}7.683^{* * *} \\
(.092)\end{array}$ & $\begin{array}{c}6.946^{* * *} \\
(.083)\end{array}$ & $\begin{array}{c}7.011^{* * *} \\
(.097)\end{array}$ & $\begin{array}{c}7.182^{* * *} \\
(.076)\end{array}$ \\
\hline No. of Clusters (Races) & 19,635 & 11,766 & 7,869 & 6,631 & 13,004 \\
\hline No. of Obs. where Dep. Var. $=1$ & 19,635 & 11,766 & 7,869 & 6,631 & 13,004 \\
\hline No. of Obs. & 183,046 & 115,023 & 68,023 & 58,417 & 124,629 \\
\hline Pseudo $R^{2}$ & 0.1372 & 0.0955 & 0.2042 & 0.1527 & 0.1293 \\
\hline \multicolumn{6}{|l|}{ Panel B: Relative Performance } \\
\hline Dependent Variable: Performance & All & Hcap & Non Hcap & Jump & Flat \\
\hline Intercept & $\begin{array}{c}-0.294^{* * *} \\
(.001)\end{array}$ & $\begin{array}{c}-0.328^{* * *} \\
(.001)\end{array}$ & $\begin{array}{c}-0.237^{* * *} \\
(.001)\end{array}$ & $\begin{array}{c}-0.265^{* * *} \\
(.002)\end{array}$ & $\begin{array}{c}-0.308^{* * *} \\
(.001)\end{array}$ \\
\hline Saboteur & $\begin{array}{c}0.153^{* * *} \\
(.006)\end{array}$ & $\begin{array}{c}0.158^{* * *} \\
(.008)\end{array}$ & $\begin{array}{c}0.139^{* * *} \\
(.011)\end{array}$ & $\begin{array}{c}0.168^{* * *} \\
(.017)\end{array}$ & $\begin{array}{c}0.162^{* * *} \\
(.007)\end{array}$ \\
\hline Predicted Percentile & $\begin{array}{c}0.005^{* * *} \\
(.00002)\end{array}$ & $\begin{array}{c}0.006^{* * *} \\
(.00002)\end{array}$ & $\begin{array}{c}0.004^{* * *} \\
(.00003)\end{array}$ & $\begin{array}{l}0.005^{* * *} \\
(.00003)\end{array}$ & $\begin{array}{c}0.005^{* * *} \\
(.00002)\end{array}$ \\
\hline No. of Clusters (Races) & 19,635 & 11,766 & 7,869 & 6,631 & 13,004 \\
\hline No. of Obs. & 171,991 & 108,045 & 63,946 & 48,054 & 123,937 \\
\hline$R^{2}$ & 0.2954 & 0.3278 & 0.2403 & 0.3494 & 0.2826 \\
\hline
\end{tabular}

Two sets of regressions to establish the benefits that accrue to the saboteur as a result of sabotage. Panel A displays coefficient estimates when an indicator variable equalling 1 if the jockey/horse won the race, and 0 otherwise, was regressed on an indicator variable equalling 1 if the jockey was guilty of sabotage during the race, and 0 otherwise, and the implied win probability (as inferred from the odds). The full sample is analysed in regression 1, with sub-samples relating to handicap, non-handicap, jump and flat races following. Panel B displays coefficient estimates when Performance, as defined in Equation (5), was regressed on an indicator variable equalling 1 if the jockey was guilty of sabotage during the race, and 0 otherwise, and the predicted percentile of the horse (as inferred from an ordering of betting odds within the race). Heteroskedasticity-consistent standard errors, clustered at the race level, are in parentheses, and $* * *, * *, *$, and . indicates significance at the $0.1 \%, 1 \%, 5 \%$, and $10 \%$ level respectively. 


\section{Figures}

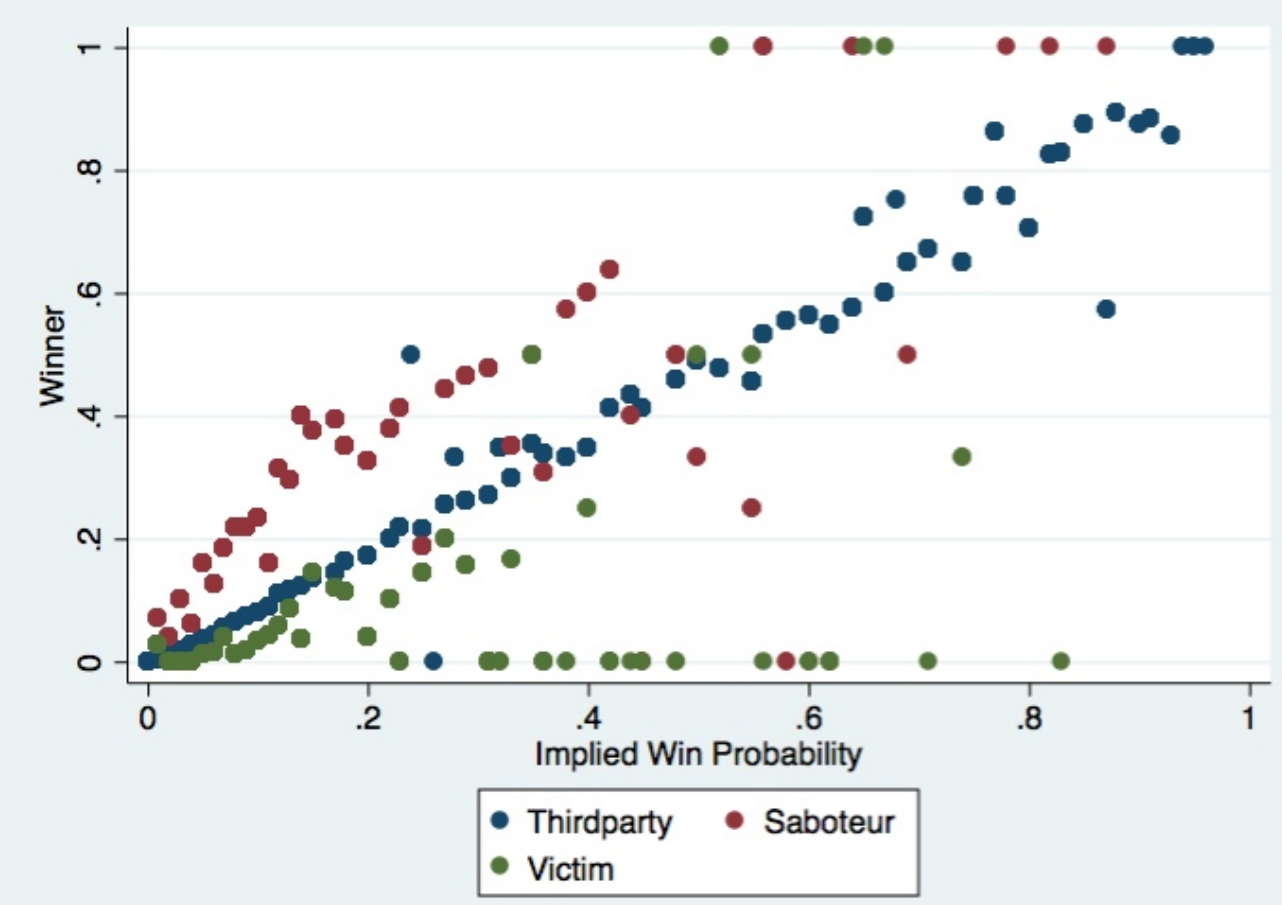

Figure 1: The average win indicator for saboteurs (red), victims of sabotage (green), and uninvolved third parties (blue). Averages are calculated for each subgroup, and for each implied win probability (inferred from the betting odds) rounded to the nearest 0.01 . 


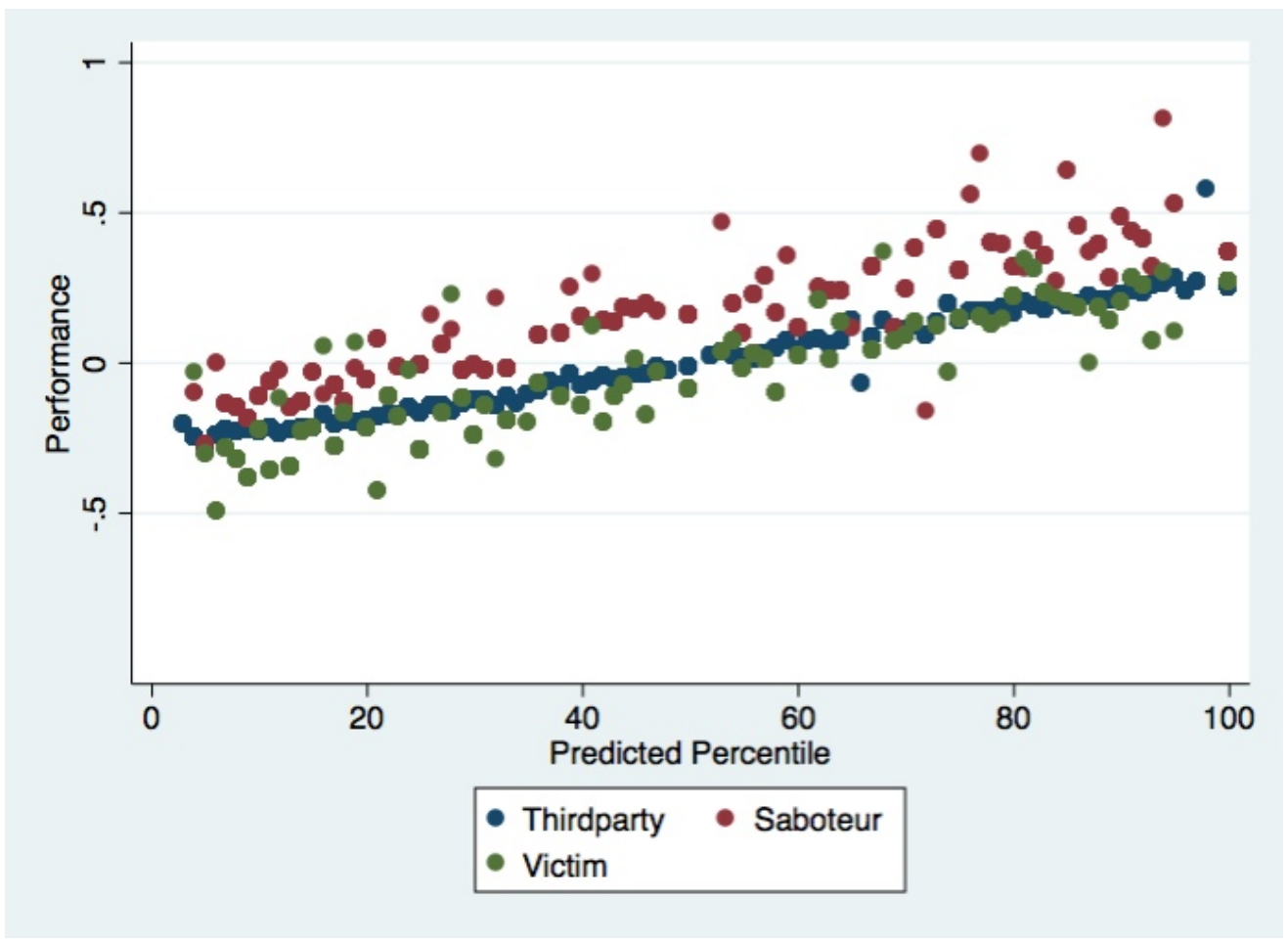

Figure 2: The average performance (as defined in Equation (5)) of saboteurs (red), victims of sabotage (green), and uninvolved third parties (blue). Average performance is calculated for each subgroup, and for each predicted percentile (as inferred from the betting odds) rounded to the nearest whole number. 